\title{
EXPERIÊNCIAS E APONTAMENTOS PARA A PESQUISA EM PSICOLOGIA BASEADA NAS ARTES
}

\author{
EXPERIENCIAS Y APUNTES PARA LA INVESTIGACIÓN \\ EN PSICOLOGÍA BASADA EN LAS ARTES
EXPERIENCES AND NOTES FOR RESEARCH IN ARTS-BASED PSTCHOLOGY

\author{
Roberta Stubs ${ }^{1}$, Fernando Teixeira-Filho² e Dolores Galindo ${ }^{3}$ \\ ${ }^{1}$ Universidade Estadual de Maringá, Maringá/PR, Brasil \\ ${ }^{2}$ Universidade Estadual Paulista - UNESP, Assis/SP, Brasil \\ ${ }^{3}$ Universidade Federal de Mato Grosso, Cuiabá/MT, Brasil
}

RESUMO: A proposta deste artigo é pensar a criação de um campo híbrido de pesquisa/experimentação na intersecção entre arte contemporânea e psicologia. Nesse sentido, exploramos o eixo arte/experiência, na intenção de produzir linhas singulares e sensíveis de subjetivação, mais afeitas ao devir e aos fluxos do que a identidades fixas. Enquanto sujeitos/pesquisadores/artistas, nossa proposta foi criar metáforas, experiências, imagens de pensamento e rasgos no que nos chega pronto, a partir da elaboração de uma figuração híbrida/plástica de corpo/subjetividade. Este foi o meio que encontramos para dar passagem para diferentes superfícies intensivas. Para tanto, valemo-nos da Metodologia de Pesquisa Baseada nas Artes e de conceitos como figuração, conexões parciais, saberes localizados (Haraway, 1995, 2013), subjetividade estética (Rolnik, 2002; Teixeira, 1993), lógica da sensação (Deleuze, 2002), entre outros.

PALAVRAS-CHAVE: Pesquisa Baseada nas Artes; Pesquisa narrativa; Arte e Psicologia; Subjetividade estética.

RESUMEN: La propuesta de este artículo es pensar la creación de un campo híbrido de investigación/experimentación en la intersección entre psicología y arte contemporáneo. En este sentido, exploramos el eje arte/experiencia, con el fin de producir líneas singulares y sensibles de subjetivación, más acostumbradas al devenir y a los flujos que a las identidades fijas. Como sujetos/investigadores/artistas, nuestra propuesta fue crear metáforas, experiencias, imágenes de pensamiento y rasgos de aquello que nos llega listo, desde la elaboración de una figuración híbrida/plástica de cuerpo/subjetividad. Este fue el medio que encontramos para dar paso a diferentes superficies intensivas. Con este fin, nos basamos en la metodología de investigación basada en las artes y conceptos tales como figuración, conexiones parciales, conocimiento situado (Haraway, 1995, 2013), subjetividad estética (Rolnik, 2002; Teixeira, 1993), lógica de la sensación (Deleuze, 2002), entre otros.

PALABRAS CLAVE: Investigación basada en las artes; Investigación narrativa; Arte y psicología; Subjetividad estética.

ABSTRACT: The aim of this article is to consider the creation of a hybrid research/experimentation field at the intersection of contemporary art and psychology. In this sense, we explore the art/experience axis, with the intention of producing singular and sensitive lines of subjectivation. Lines that are more akin to becoming and to the flows than to fixed identities. While individuals/researchers/artists, our proposal was to create metaphors, experiences, images of thoughts and tears in what come to us as ready-made by creating a hybrid figuration/plastic body/subjectivity. This was the way we found to make different intensive surfaces flow. To do so, we followed the Arts Based Research Methodology, and concepts such as figuration, partial connections, located knowledges (Haraway, 1995; 2013), aesthetic subjectivity (Teixeira, 1993; Rolnik, 2002), the logic of sensation (Deleuze, 2002), among others.

KEYWORDS: Arts Based Research; Narrative inquiry; Art and Psychology; Aesthetics subjectivity. 


\section{Introdução}

Apostando na produção de modos de subjetivação mais inventivos, a proposta deste artigo é pensar maneiras de fazer pesquisa em Psicologia, utilizando a arte como uma ferramenta para viabilizar linhas de subjetivação mais abertas a canais de diferenciação que de reprodução dócil da realidade, sendo esta ferramenta a Pesquisa Baseada em Artes de enfoque narrativo. Para tanto, valemo-nos aqui da nossa experiência enquanto psicólogo/as, artistas e pesquisadores/as, assim como de nossos experimentos estéticos no território híbrido que se forma na conjugação entre Psicologia e Arte Contemporânea. Conceitos como conexões parciais e saberes localizados, cunhados por Donna Haraway (1995), assim como a metodologia de Pesquisa em Psicologia Baseada nas Artes, serão aqui discutidos para fundamentar nossa investigação e para pensar a produção de modos de subjetivação inventivos.

$\mathrm{Na}$ tentativa de ultrapassar os binarismos que acometem a pesquisa em Psicologia e em ciências humanas em geral, os quais tendem a separar o sujeito pesquisador (dono de uma verdade sempre em busca de comprovação) e o objeto de pesquisa (passivo e à mercê de ser desvelado e interpretado), apoiamo-nos em uma proposta que tenta favorecer a experiência e se coloca contrariamente aos mecanismos de totalização, racionalização e generalização que eliminam as dúvidas, as dissonâncias e os fluxos de diferenciação.

Nesse sentido, concordamos com Haraway (1995), quando afirma que todo conhecimento é situado e corporificado, sendo, portanto, capaz de ser responsável pela posição que ocupa e desdobramentos que gera. Segundo a autora, o conhecimento situado vale-se de uma perspectiva parcial, capaz de produzir uma visão objetiva ligada ao presente da experiência, e não às promessas metafísicas de verdades absolutas. A autora afirma que o único meio de encontrar uma visão mais ampla é situando-se em algum lugar em particular, concepção que desvela todo um flanco de conversação, ao possibilitar aberturas inesperadas, visto que contempla a perspectiva de "pontos de vista, que nunca podem ser conhecidos de antemão" (Haraway, 1995, p. 24).

Seguindo as pistas de Donna Haraway, a Pesquisa em Psicologia/Arte pode proceder por conexões parciais e produzir um conhecimento localizado, situando-se no campo de experiência que emerge no movimento do pesquisar. Essa perspectiva facilita a inscrição ativa de todos os envolvidos no processo de pesquisa, favorecendo que todos sejam também produtores de conhecimento. Assim, assumimos a parcialidade e a localização limitada do conhecimento por nós produzido, para então alçar voos rumo à produção de um saber aberto, o qual pode ser invocado e multiplicado em outras localizações possíveis, porém, sem nunca generalizar e anular as singularidades. Com essa postura, delineamos os contornos deste texto, ocupando e criando um espaço de experimentação enquanto psicólogo/as, artistas e pesquisadores/as.

\section{Pesquisa em psicologia baseada nas artes (PPBA)}

Uma das maiores dificuldades para quem se localiza no território hibrido que insurge na intersecção entre Psicologia e Arte Contemporânea é encontrar uma metodologia que possibilite falar sobre arte e produção artística produzindo arte, saindo, portanto, do campo da representação para o campo da experimentação propriamente dita. Em resposta a essa necessidade, encontramos na Metodologia de Pesquisa Baseada nas Artes (PBA) 
uma maneira de contemplar a inventividade, os acasos e a processualidade que perpassam todo o processo de pesquisa, criação e experimentação artística e conceitual. Iniciada na década de 1980, a PBA é uma forma de investigação que proporciona maior conhecimento das atividades humanas via diferentes meios artísticos: música, teatro, dança, artes visuais e plásticas, performances e literatura (Irwin, 2013). Ainda segundo a autora, a PBA está interessada em melhorar perspectivas sobre a produção humana, engendrando uma percepção expandida e aberta para ressignificações.

Nesse sentido, entendendo que toda atividade artística envolve um processo de investigação teórico, estético e prático, a PBA nos dá as bases necessárias para falar e pensar sobre a arte fazendo arte. Dessa maneira, a PBA envolve não apenas a investigação e interpretação sobre a arte, mas também o processo de criação propriamente dito, incluindo o fazer artístico no campo de investigação. Algo interessante nessa metodologia é que o próprio pesquisar é considerado um processo criativo, fato que autoriza o pesquisador a fazer arte como meio de fundir a teoria e a prática, em seu processo de investigação. De acordo com Hernández (2013), a PBA utiliza em seu processo de pesquisar: elementos artísticos e estéticos, relacionados com as artes visuais ou performativas; busca outras maneiras de olhar e representar a experiência como forma de ampliação de perspectivas sobre os fenômenos abordados; trata de desvelar aquilo do qual não se fala, propondo uma conversação mais ampla e profunda sobre as políticas e práticas, tratando de revelar aquilo que costuma se dar como fato e que se naturaliza.

Dentre as tendências de Pesquisas Baseadas nas Artes (PBA), podemos citar três campos amplos de trabalho: a perspectiva literária, a perspectiva artística e a perspectiva performativa. A perspectiva literária emprega formas literárias de expressão, como a poesia e a mistura de histórias reais com ficção, quer para contar a experiência de quem fala, quer para gerar uma fenda para os leitores refletirem e preencherem com suas próprias experiências e histórias. Ou seja, essas narrativas podem ou não misturar eventos vividos como ficcionados.

Partindo da metodologia da Pesquisa Narrativa de Clandinin e Connelly (2000), o pesquisador ou narrador não somente coleta histórias, mas é alguém que está dentro da narrativa, um personagem vulnerável e em crise. A ideia geral da pesquisa narrativa e seu desdobramento na perspectiva literária do PBA seria "contar uma história que permita a outros contar a sua. $\mathrm{O}$ objetivo não seria somente apreender a realidade, mas produzir e desencadear novos relatos.” (Hernández, 2013, p. 47). O que acaba por acontecer, nessa perspectiva, é a incorporação do leitor na própria escritura do texto, através da ativação de sua própria experiência de vida via ressignificação de sentidos e abertura à reflexão sobre si e sobre o outro, como nos dirão Clandinin e Caine (2008, p. 541):

A Pesquisa Narrativa é antes de tudo uma forma de entendimento da experiência. É também uma metodologia de investigação. É, então, tanto uma visão dos fenômenos de experiências das pessoas quanto uma metodologia para narrativamente investigar as experiências e, portanto, permite o estudo íntimo das experiências dos indivíduos ao longo do tempo e no contexto.

Sobre a perspectiva artística, esta tem como base a utilização de formas de expressão artísticas visuais, como pinturas, fotografia e imagens em geral, colocando em relação, muitas vezes, a imagem e o texto. Sobre a relação texto e imagem, é importante pontuar a necessidade de que ambos tenham uma certa consistência e autonomia, as quais se sustentem separadamente, porque somente assim a complementaridade entre os dois será 
mais completa. Nessa perspectiva, as imagens ganham destaque enquanto registro de momentos e ilustração da narrativa, abrindo um campo de significados ligados à imagem. A imagem pode ser usada como registro de histórias ou sua recuperação, de modo a servir de disparador de narrativas.

A perspectiva performativa, por sua vez, está centrada na prática e na ação artística, atribuindo importância central ao corpo enquanto centro da experiência. Do ponto de vista performativo, a noção de sujeito ganha outros contornos, pois, ao enfatizar a experiência "encarnada" do mesmo, o foco passa ser a construção descentrada e fragmentada desse sujeito processual.

Segundo Vidiella (citado por Hernández, 2013, p. 54), o relato performativo se propõe nos "fazer repensar sobre nossas posições, localizações, sobre nossos papéis como criadores e/ou espectadores, colapsando as fronteiras entre artista-obra de arte; artista-espectador e obra-espectador". É importante assinalar que as três perspectivas citadas não esgotam as infinitas possibilidades de PBA, contudo, permitem a criação de combinações incontáveis sobre possíveis pesquisas que almejem ser tanto produções acadêmicas quanto produções artísticas.

O conjunto dos tópicos citados dá passagem a aspectos mais ligados ao acaso, à experiência subjetiva do pesquisador e do interlocutor, às sutilezas e ao transitório, aos afetos e às emoções. Esses elementos estão mais próximos da sensibilidade do que especificamente da racionalidade; na verdade, trata-se de uma razão sensível que mobiliza tanto aspectos intelectuais e cognitivos quanto artísticos e estéticos. Por conta desses fatores, a PBA carrega uma qualidade artística e criativa que nem sempre encontramos nas metodologias acadêmicas mais tradicionais, pois possibilita a criação de formas de comunicação que combinam o visual, o musical, o literário ou o performativo com aspectos conceituais, sociais, pessoais e estéticos.

Invocando a produção de um conhecimento sensível e sempre disposto a ressignificações, podemos asseverar que esse modelo de fazer pesquisa se faz dentro de uma perspectiva ético-estética-política da existência (Guattari, 2000) que corrompe a racionalidade, por se insinuar no plano das sensações e da criação de outros espaços possíveis de experimentação de si e do mundo.

Nesse sentido, mais do que confirmar hipóteses, o processo de pesquisar se torna um convite para criar novos universos de referência abertos à experimentação de espaços de sentido situados. A proposta é gerar redes de conexões, ao invés de somente informar resultados do que foi realizado na pesquisa, criando cortes, rupturas e fendas, as quais resistam à previsibilidade e possam ser ocupadas por outros processos de pesquisa, outras possibilidades de experimentação. Nessa perspectiva, a pesquisa passa a ser crítico-inventiva, e o pesquisador, um capacitador de fluxos e processos de diferenciação. Aqui, psicólogo/artista/pesquisador se confundem, sendo dada ao psicólogo a tarefa não somente de interpretar os fatos, mas de criar e dar vazão a novas e outras formas de ser, estar, desejar e experimentar o mundo. É a partir dessa perspectiva que podemos também falar numa metodologia de Pesquisa em Psicologia Baseada nas Artes (PPBA)

A proposição de um modo de pesquisar inventivo, assim como a ideia de que o psicólogo/artista/pesquisador é um capacitador de fluxos e experiências, incorpora a premissa deleuzeana de que pensar é sempre experimentar (Deleuze, 2006). Para além de um conhecimento pautado apenas na racionalidade e na busca de verdades, o autor afirma que "a experimentação é sempre o atual, o nascente, o novo, o que está em vias de se fazer" 
(Deleuze, 2006, p. 132), fato que nos lança numa aventura de fazer ciência e produzir um conhecimento sensível, parcial e localizado, sempre em vias de ressignificação. É nessa aventura que embarcaremos agora, convidando os leitores a conhecer pistas e memórias de algumas experiências realizadas na intersecção entre Arte Contemporânea e Psicologia. Percorrendo algumas experiências/instalações/oficinas realizadas pela artista/psicóloga Roberta Stubs, em seu Doutoramento (Stubs, 2015), decidimos aqui, utilizando um tom narrativo, escrito em primeira pessoa e parcialmente ficcional, criar uma figuração sobre nossa inserção na contemporaneidade, empregando o corpo como elemento central.

O corpo ganha destaque por ser a superfície encarnada de nossa subjetividade, um território profícuo para a produção de experiências singulares e para a produção de relações desejantes com o mundo, via práticas de liberdade. O corpo, portanto, não é apenas uma carne recheada de ossos e vísceras, o corpo é político e habita um espaço de disputas que o querem passivo, obediente e limitado por práticas de assujeitamento. Não queremos esse corpo dócil, queremos um corpo que vibra, sente e se experimenta.

\section{A trajetória de um corpo em experiência: Psicologia e Arte Contemporânea}

Neste subtópico do manuscrito, escrevemos, na modalidade narrativa, em primeira pessoa do singular. Trata-se de uma ficção teórica criada a partir da experiência enquanto artista, professora e pesquisadora de uma das autoras do texto. Escrever em primeira pessoa do singular é uma maneira de gerar uma política de localização de saberes, a qual passa a acolher as palavras também em primeira pessoa daquele ou daquela que lê. Trata-se de um texto performativo que, como esclarece Andreotti (2016, p. 1), "são muito diferentes dos textos que buscam representar algo literalmente. Como expressão de uma força estética, o texto tem uma vida própria" que escapa ao controle de quem o escreve, dependendo dos efeitos produzidos no contato com os leitores e leitoras.

O plástico é frio, é artificial, e serve como prótese que separa do que posso, que não deixa passar as forças de que precisamos para fazer o corpo vibrar. O estranho é que minha própria carne, que não é de plástico, várias vezes parece fria. Porém, se penso, com Deleuze, que o mais profundo é a pele, e sei que ela é o maior órgão de nosso corpo, encobrindo toda minha superfície corporal, suspeito também que tê-la imobilizada vá interferir em minhas mais íntimas camadas. Não quero que meu corpo deixe de pulsar desejo e produção. Não quero ser apenas uma pele seca que perambula pela vida, sem senti-la ou sentindo-a pela metade.

É preciso dizer que certo dia saí de carro pela cidade onde moro, que pode ser qualquer lugar. Acostumada que eu estava a olhar para os desvios e curvas de meus caminhos, vi um manequim de plástico pendurado num latão de lixo. Era um corpo de plástico, tamanho criança. Estacionei, fotografei e adotei esse infante como minha companhia. $\mathrm{O}$ plástico sempre me disse algo do orgânico, e um corpo de plástico me dizia ainda mais. $\mathrm{O}$ fato de tê-lo encontrado no lixo também era, no mínimo, interessante. Aquele corpo tinha uma memória, era um pedaço de plástico com uma pele suja e marcada de história. O que ele contava para mim? O que eu contaria a partir dele? $\mathrm{O}$ que me ligava e/ou distanciava daquele corpo? Logo transformei aquele corpo-plástico-orgânico numa figuração para pensar a inserção de nossos corpos no contemporâneo. 
Uma tecnologia de anestesiamento do potencial expansivo do corpo, este é um dos efeitos do plástico em nós. Uma tecnologia da pele que incide sobre nossos corpos, para amortizá-los e anestesiá-los. Nos séculos XX e XXI, as próteses poliméricas vinculadas a grandes corporações se insinuam como tecnologias potentes para o silenciamento dos corpos e afecções, por meio de membros que pouco ou quase nada adicionariam em termos de sensações com privilégio de uma pretensa funcionalidade, a qual, mesmo com os acoplamentos neurossensíveis mais recentes, reforçam o privilégio de algumas maneiras de prazer e não outras, de alguns modos de viver e não outros. Contudo, esses mesmos polímeros se colocam como suportes para contracondutas, através da sua reversão em tecnologias de produção de outras economias subjetivas e prazeres (Preciado, 2015). Silicone, maquiagens, pílulas e hormônios fazem parte do universo polimérico que nos transformam em manequins e corpos moldáveis. Corpos moldados para não ter memória, para reproduzirem desejos e práticas predefinidas. Corpos que giram infinitamente num mesmo eixo até ficarem tontos e caírem mortos, ou saírem por aí como zumbis que, como criaturas de ficção, frequentam nossas imaginações que a eles se confundem na anestesia e dificuldade para traçar planos de existência consistentes (Rolnik, 2015). Um corpo todo encapado de rótulos que nada dizem da potência de expansão da vida. Um corpo capturado e de sensações anestesiadas; uma casca.

Em minha pele, essa enorme superfície de inscrição, há marcas e que há anos se acumulam e formam uma casca de impermeabilização. Um corpo capturado e de sensações anestesiadas; uma casca. Preciso sentir que não sinto mais, perceber que nada mais me afeta e decidir que não quero essa casca em mim. Não quero nada que me amorteça os sentidos. Essa casca precisa virar casulo e, de dentro dele, outra pele e outro corpo precisam nascer. Fazer a casca virar casulo. Fecho meus olhos e me visualizo toda envolta em plástico girando, girando, até meus poros sufocados pedirem por oxigenação: o processo é gravado em vídeo. $\mathrm{O}$ corpo se torna poroso às sensações do mundo.

\section{Figura 1: Corpo poroso}

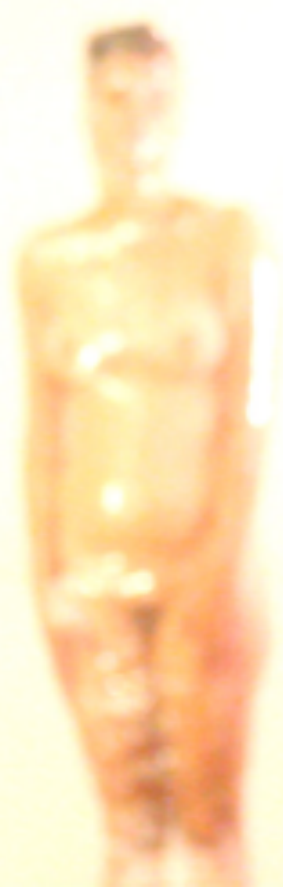


Eu me torno vulnerável às alterações de pressão e calor que transformaram minha casca em casulo e ativaram o aspecto de maleabilidade e moldabilidade próprias de um elemento plástico. Descubro que posso fazer meus próprios moldes, sem perder a abertura para mundo, sem abrir mão do devir que não cessa em me apresentar a novos territórios. A luminosidade atravessa a carne, vou sendo atravessada pela tranquilidade de um vir a ser que não teme a desconstrução, pois se sabe repleto de passagens e permanências. Foi quando entrei na Unidade de Multiplicação de Eu’s (Figura 2) e me confrontei com meu rosto infinitizado num jogo de espelhos que estava ali para descentrar e abrir minha subjetividade para um eu-somos. Numa instalação artística, a sala passa a ser o corpo, que nela se inscreve e, paradoxalmente, se aparta:

Figura 2: Instalação plástica-orgânica de multiplicação de eu’s

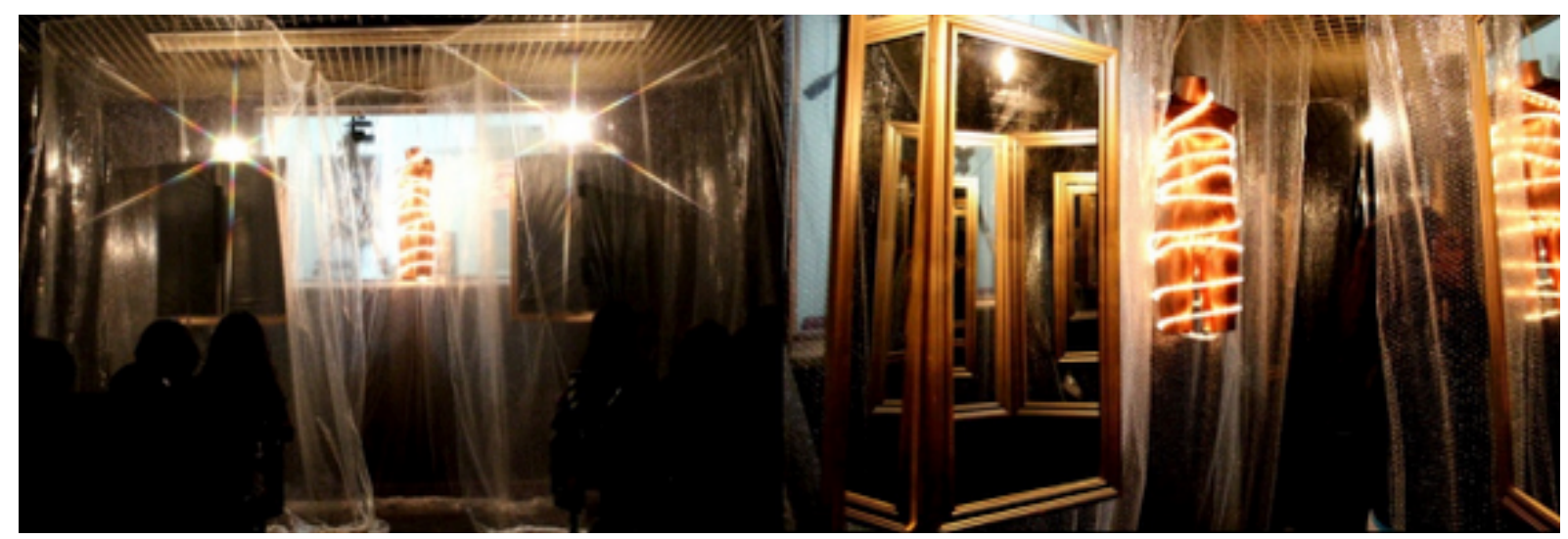

No centro da instalação, um corpo plástico de pele dourada todo em luz e neon cintilava e invadia minha retina, dizendo ser possível abrir-se às sensações. Sim, aquela luminescência ofuscava meus territórios acostumados, amolecia a camada de casca que envolvia minha pele e me abria para algo que ainda desconhecia. Foi aí que percebi que aquela luz apontava para a dimensão maleável do plástico, um estrato de vida no qual não precisávamos ser dóceis, tampouco andar somente em linha reta. Era preciso seguir essa pista de luz, imergir nesse emaranhado de linhas duras e flexíveis, entrar num combate sem fim pelo que flexibiliza e amplia nossos campos existenciais.

Um combate sem fim diz de um processo constante de dobrar-se, (re)dobrar-se e (des) dobrar-se imersos num emaranhado de linhas que nos subjetivam por todos os lados, e com as quais tanto podemos nos singularizar quanto nos assujeitar. Já sabemos que os processos de singularização são alvos de captura, sendo inclusive fonte de renovação para o Capitalismo Mundial Integrado (CMI) e seus investimentos capitalísticos, os quais forjam subjetivações maquínicas atravessadas por um socius heterogêneo. O termo capitalístico é utilizado por Guattari (1990) para incluir o campo da economia subjetiva no plano da economia política.

A criação de outros relevos e suavidades com o mundo passa, necessariamente, pela ativação de nosso corpo sensível, de nossas sensações. Foi nessa ideia que insisti, quando comecei a emplastificar corpos (Figura 3). Pela emplastificação de corpos, conduzidas em oficinas, eu sufocava os poros do corpo com plástico-filme, despertava um desejo e necessidade de oxigenação que, então, davam passagem a novos fluxos. Durante o processo da oficina, após algumas experimentações, as pessoas ficavam deitadas todas envoltas em plástico-filme e se contorcendo até romper as camadas de plástico. Produzíamos um corpo 
híbrido, cujos resquícios de artificialidade e inorganicidade desaparecessem, no ato de rompimento do casulo plástico.

Figura 3: Corpos-casulos, oficina de emplastificação

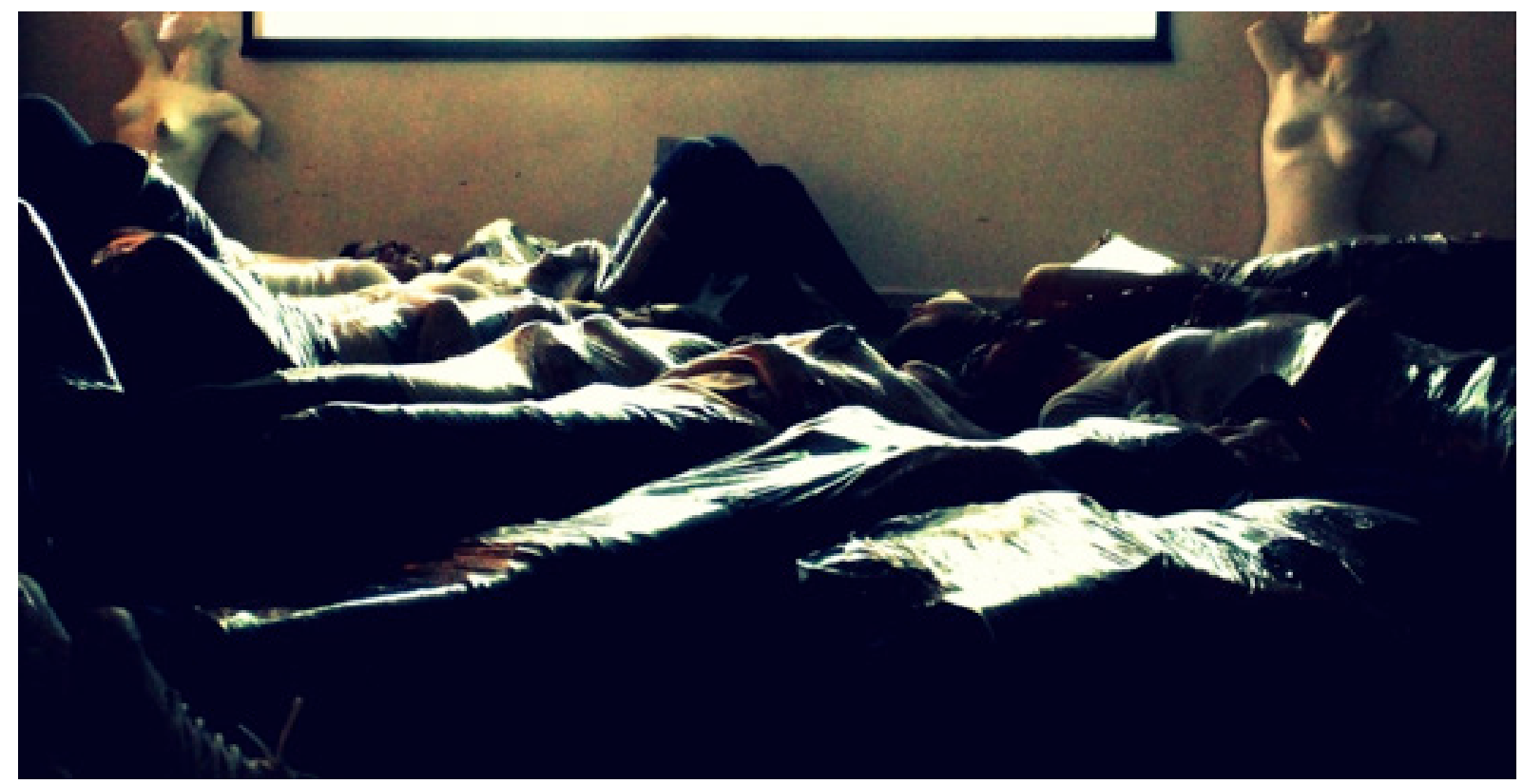

Porém, já é sabido, as marcas permanecem e geram bifurcações em nossas subjetividades, e ali nasciam linhas que apontavam para uma política de vizinhança entre a carne e o plástico, entre razão e sensação, entre a Psicologia e a Arte. Essa prótese-plástica trabalha para a ativação de nosso corpo vibrátil (Guattari \& Rolnik, 1999), ativação que nos abre para exercícios de liberdade conosco, com o outro, com nossos desejos e com a própria prática do pensamento. O que está em tela é a potência dos corpos fazer vibrar a música do mundo, traçando linhas de fuga ao anestesiamento.

Explorando o lugar de fronteira entre a Psicologia e a Arte, eu estava criando um espaço de ação e intervenção capaz de escapar da dimensão ortopédica da Psicologia, ao acionar possibilidades de ações mais inventivas e livres ao campo da experimentação. $\mathrm{O}$ plástico era o canal de ressignificação de nossos territórios existenciais, de ampliação em potência de nossos campos de experiência, de potencialização de nossa capacidade de afetar e ser afetado. Esse artefato protético me leva ao campo do sensível, esse imenso campo de forças que circula em imanência. As afetações não possuem hierarquia, são donas de uma inalienável disposição ética ao respeito às várias formas de viver, independentemente de cor, espaço, volume ou variação.

\section{Figuração como operador para a Pesquisa em Psicologia baseada nas Artes}

A fim de aprofundar o entendimento do relato/experiência acima narrado, é importante esclarecer alguns termos e estratégias por nós empregados. Inicialmente, é válido investir mais detidamente na palavra figuração, termo para se referir ao corpo-plástico-orgânico. Considerando a necessária desconstrução do sujeito moderno, dotado de essências 
e de uma identidade imutável, incorporamos neste texto a crítica radical realizada pelo feminismo pós-estruturalista e pela teoria queer. Essa crítica radical pede, necessariamente, a criação de novas figuras de pensamento e ferramentas conceituais para pesquisar os processos de subjetivação.

Foi nessa perspectiva que Donna Haraway cunhou o termo figuração. Para a autora, pensar e criar figurações para a subjetividade contemporânea é tanto uma maneira de exercitar a imaginação para visualizar novos contornos à subjetividade, quanto uma forma de situar essa figura da subjetividade em determinado espaço-tempo social. O conceito de figuração, a partir do trabalho de Donna Haraway, e a sua tradução como ferramenta metodológica vêm sendo desenvolvidos na Psicologia para cartografar as linhas duras do presente e a elas traçar linhas opositivas (Galindo, Méllo, \& Milioli, 2013; Milioli \& Galindo, 2015; Stubs, 2015).

Segundo Braidotti (2000, p. 28), a criação de figurações outras para a subjetividade diz de um comprometimento radical com a tarefa de subverter as representações e perspectivas convencionais acerca da subjetividade humana, especialmente no que tange à subjetividade da mulher. Braidotti (2002) salienta que a criação dessas figurações outras e híbridas para a subjetividade é uma estratégia política, epistemológica e imaginativa de abandonar as identidades fixas como um local sedentário. Ainda conforme a autora, essas figurações são comuns a algumas teorias feministas que têm produzido poderosas ficções políticas para desontologizar o sujeitx, como assevera Preciado (2011), e refigurar a mulher não enquanto outro do homem, mas como um Outro múltiplo, deslizante:

Monique Wittig (1991) escolhe chamar o (pós-mulher) sujeito feminista - lesbiana - o que é ecoado por Judith Butler (1991), com a "política paródica da mascarada”. Nancy Miller (1986) denomina “mulher" - fêmea, feminista, sujeito de outra história. De Laurettis (1990) a chama "sujeito excêntrico"; Trinh Minh Há (1989) "o outro inapropriado"; Spivak (1995) "o sujeito pós-colonial”; Alice Walker (1984) "a mulherista” (womanist); Glória Anzaldua (1987) trabalhando a partir da área de NAFTA aponta-a como a "mestiza”. (Braidotti, 2000, p. 11).

Haraway cria a figura do ciborgue "como uma ficção que mapeia nossa realidade social e corporal e também como um recurso imaginativo que pode sugerir alguns frutíferos acoplamentos" (Haraway, 2013, p. 37). Reiterando a necessidade de uma perspectiva não naturalista que transcenda uma visão cunhada em unidades identitárias, Haraway (2013) aponta a subjetividade ciborgue como figura híbrida de ligação homem-mulher-máquina/ homem-mulher-mundo. Haraway incorpora em seu híbrido discussões do feminismo contemporâneo sobre as tecnologias de gênero (Laurettis, 1994), ou de sexo (Preciado, 2008), com respeito às biopolíticas que engendram corpos de mulher e de homem, dentro desse sistema sexo/gênero/desejo/tecnologia. O híbrido seria uma figura "pós-identitária”, a qual ultrapassa os mecanismos binários que formatam nossa subjetividade, ao lançar o corpo em um território de fronteira, mais afeito à experiência que à representação.

Os ciborgues, por sua vez, se inscrevem num contexto de avanço da biotecnologia, da nanotecnologia, da eletrônica e afins, "vivem em um mundo intimamente reestruturado por meio de relações sociais da ciência e tecnologia que estariam gerando novas formas sociais que por sua vez demandam novas formas de compreensão" (Galindo, 2003, p. 5). Inseridos nesse mundo reestruturado pelos avanços tecnológicos, uma subjetividade ciborgue ganha 
forma via conexões e vizinhanças, as quais podem se estabelecer parcialmente, contendo também dissensos e dessemelhanças. "Longe de assinalar uma barreira entre as pessoas e os outros seres vivos, o ciborgues assinalam um perturbador e prazerosamente estreito acoplamento entre eles" (Haraway, 2013, p. 40).

Nessa perspectiva, a figuração plástica-orgânica é uma variação desse corpo/subjetividade ciborgue, o qual se encontra inscrito num tempo de capturas biopolíticas, mas se sabe capaz de ultrapassar os limites do presente, ao explorar novos contornos para este agora. Mais do que vestir a subjetividade que nos chega pronta e acabada, um corpo-plástico-orgânico pode conjugar essas linhas de subjetivação com maior autonomia, explorando mais a dimensão da plasticidade conectiva e performática do corpo do que do endurecimento e moldabilidade da casca. Nesse sentido, o corpo-plástico-orgânico contém a ambiguidade de um tempo que tanto investe na docilização dos corpos quanto possibilita movimentos de resistência e criação via conexões híbridas, parciais e sensíveis.

Sobre essa dimensão de resistência e criação, Penedo (2008, p. 116) afirma que, em um contex to biopolítico, o ciborgue de Haraway se perfila enquanto identidade estratégica no sentido apontado pelos teóricos queers que afirmam que as identidades são sempre múltiplas. Na perspectiva ciborgue, podemos falar em uma concepção pós-identitária, na qual a afinidade substitua a identidade e a conexão seja uma fonte inesgotável de heterogênese. Nesse contexto, os fluxos e devires que compõem os processos de subjetivação não serão motivos de medos sobre uma possível e iminente desintegração do eu. Pelo contrário, os fluxos e devires se tornam um material inesgotável de possibilidades conectivas, fonte gerativa de formas de viver ainda sem nome, medida ou representação.

Um outro plano convocado por nós, na ficção-relato-experiência narrada, foi o plano das sensações. Em vários momentos, mencionamos a necessidade de acionar a capacidade vibrátil do corpo e ampliar sua capacidade de afetar e ser afetado. De acordo com Deleuze, a lógica da sensação afeta diretamente o corpo, contornando e corrompendo o primado da representação e dos modelos mentais e existenciais cunhados por instituições de saber e poder. Por ser transmitida diretamente, a sensação é da ordem do movimento e do devir, um processo contínuo de produção de sensações que desestabilizam o corpo, as pálpebras e a pele, ao serem tocados.

Um corpo tocado e ativado sensorialmente é um corpo que vibra, não anestesiado, um corpo potente e disposto a inventar-se, ao se colocar em movimento. Enfatiza Deleuze (2002, p. 42) que "a sensação é o contrário do fácil e do lugar-comum, do clichê, mas também do 'sensacional', do espontâneo, etc.". No sentido dado pelo autor, a sensação ocorre na mistura indissolúvel entre o sujeito (corpo no mundo) e o objeto (fato no mundo), estando contida virtualmente, quando aludimos a uma obra de arte, por exemplo, tanto na pele daquele que vê uma obra ou experimenta uma instalação quanto na própria obra. Ao pensar a relação das pessoas com os objetos estéticos (pintura, instalações, vídeos, fotografias etc.), podemos dizer que a sensação ganha passagem no acontecimento que marca o encontro entre sujeitx e obra, configurando-se como um elemento importante para que ocorra uma experiência singular ou uma experiência estética.

Pela lógica da sensação, uma obra de arte nunca é um "ser acabado que existe em si como uma coisa, mas sim, um convite à sensação, à experiência... “ (Braga, 2004). Nesse sentido, as expressões artísticas nos convidam constantemente a ativar esse campo de sensações, sendo essa uma maneira de nos ligarmos a intensidades que compõem a obra, que a qualificam esteticamente. Não podemos deixar de apontar que a lógica da sensação, 
em Deleuze, está intimamente ligada à sua leitura de Espinosa e à imensa influência que o pensamento imanente desse filósofo exerceu, na filosofia de Deleuze. O que pode o corpo? - Perguntou Espinosa. Para o filósofo, os corpos e os pensamentos eram definidos pelo poder que tinham de afetar e ser afetados: "Definiremos um animal ou um homem não pela sua forma, seus órgãos e suas funções, e tampouco como um sujeito: nós o definiremos pelos afectos de que é capaz" (Deleuze, 1981/2014, p. 11). Dessa forma, tanto a razão quanto a emoção crescem e se ampliam via afecção, via expansão de nosso corpo de sensação.

Para Deleuze e Guattari (2005), a arte é capaz de criar um bloco de sensações que diz da passagem da alteridade empenhada numa matéria de expressão, um composto de diferenças e diferenciações que nos lançam constantemente num devir-sensível, ato pelo qual algo ou alguém não para de devir outro. Ao sermos tocados pelo campo sensível da arte, passamos por uma espécie de desenquadramento, o qual nos abre e nos fende para o que os autores chamam de um cosmo infinito de mundos e sensações possíveis. Esse movimento acontece não pela projeção mental de mundos, mas, na encarnação total desses mundos, a arte é colorante, ela cria universos sensíveis que geram aberturas em nosso corpo/subjetividade.

Este é o convite feito nesta pesquisa quando usamos o ciborgue plástico-orgânico ou as próteses poliméricas para acionar a capacidade plástica, sensível e vibrátil do corpo. São estratégias para ativação de um campo sensorial que acessa e afeta diretamente nosso corpo de sensação, mobilizando uma potência de expansão, ao fazer nascer linhas de subjetivação abertas a exercícios experimentais de liberdade. Sufocar poros e emplastificar corpos constituíram uma via de dar vazão e ênfase às sensações, ao tirá-las do campo de anestesiamento para ativar novos processos de subjetivação. Precisamos sentir que não sentimos nada, para voltar a sentir novamente e, tal como proposto por artistas como Lygia Clark, Helio Oiticica e Ligya Pape, expandir nossa capacidade de afetar e ser afetado.

\section{Considerações finais}

Quando criamos, na pesquisa, o corpo-plástico-orgânico como fio condutor de nossa narrativa, convocamos um exercício imaginativo para pensar nosso pertencimento a um mundo híbrido e vasto em possibilidades. As experiências invocadas e figurações criadas nos situam na ambivalência de nosso tempo e apontam para possíveis ultrapassamentos. É como operadoras de desconstrução e abertura do corpo/subjetividade às sensações que a emplastificação trabalha; por uma política do sensível, sem hierarquia, sem restrições de cor, espaço, volume ou variação.

Foi explorando o eixo arte/experiência que tentamos produzir linhas singulares e sensíveis de subjetivação. Sobre esse aspecto, Teixeira-Filho (1993) e Rolnik (2002) utilizam o termo subjetividades estéticas, para se referir a um modo de subjetivação vibrátil e sensível, disposto a movimentos de criação e de devir, abertos à desconstrução de outros e novos universos de referência, assim como à ressignificação de si e do mundo. Segundo Rolnik, investir em subjetividades estéticas mobiliza o desenvolvimento de uma capacidade de reciclagem do repertório existencial e promove a abertura para outros modos de ser, estar, desejar e se relacionar no e com o mundo.

Enquanto sujeitos/pesquisadores/artistas, nossa proposta foi criar metáforas, experiências, imagens de pensamento e rasgos no que nos chega pronto, através da criação de 
uma figuração híbrida/plástica de corpo/subjetividade. Este foi o meio que encontramos para dar passagem a diferentes superfícies intensivas. Nosso foco foi produzir linhas de subjetivação singulares, subjetividades estéticas afeitas ao sensível e à (des)construção de outras suavidades no mundo. Ao relatar essa experiência de fronteira, tentamos dar visibilidade a pequenos/grandes pontos de fusão entre: arte e psicologia; processo criativo e processo de pesquisar; falar e produzir subjetividade; pensar e experimentar o pensamento. Isso tudo, colocando em conversação diferentes campos criativos: literários, clínicos, visuais, imagéticos, experimentais.

Num contexto marcado pela gestão e controle da vida, corpos e desejos, o campo de experiências possibilitado pela arte e pela criação desses espaços híbridos nos convida à criação de novas formas de nos relacionarmos com e no mundo, inventando novas suavidades e semióticas de sentido que reverberem relações de vida e produção desejante. Estabelecer vizinhanças entre diferentes expressões artísticas, a Psicologia e o processo de pesquisar se configura como um desses campos em vias de significação e invenção. Um imenso território crítico-inventivo que acredita na potência da imaginação para criar saídas e fugas ao pensamento binário e à estratificação do saber/poder que nos captura por todos os lados, segmentando e empobrecendo esses diferentes campos de saber. A Pesquisa em Psicologia baseada nas Artes, que toma a figuração como prática metodológica, se configura como um caminho para experimentações.

\section{Referências}

Andreotti, V. (2016). Other Education. The Journal of Educational Alternatives, 5(1), 2049-2162.

Braga, E. C. (2004). Arte e sensação: A natureza sintética da sensação na experiência artística segundo Gilles Deleuze. Revista Digital ArtÉ, 2(1), 1-9.

Braidotti, R. (2000). Sujetos nómades. Buenos Aires: Paidós.

Braidotti, R. (2002). Diferença, Diversidade e Subjetividade Nômade. Estudos Feministas, 1-2, 1-16.

Clandinin, D. \& Caine, V. (2008). Narrative Inquiry. In L. M. Given (Org.), The Sage encyclopedia of qualitative research methods (pp. 541-544). NY: Sage.

Clandinin, D. J. \& Connelly, F. M. (2000). Narrative Inquiry: experience and story in qualitative research. San Francisco, CA: Jossey-Bass Publishers.

Deleuze, G. (2002). Francis Bacon. A lógica da sensação. Rio de Janeiro: Zahar. Deleuze, G. (2006). Conversações. São Paulo: Ed. 34.

Deleuze, G. (2014). Spinoza - Philosophie pratique. Paris: Éditions du Minuit. (Obra original de 1981).

Deleuze, G \& Guattari, F. (2005). O que é a filosofia? São Paulo: Editora 34.

Galindo, D. Sobre os ciborgues como figuras de borda. Athena Digital. Revista de Pensamiento E investigación Social, 4, 1-15.

Galindo. D., Milioli, D. \& Méllo, R. (2013). Dançando com Grãos de Soja, Espécies Companheiras na Deriva Pós-Construcionista. Psicologia \& Sociedade, 25(1), 48-57. 
Milioli, D. \& Galindo, D. (2015). Subjetivações selvagens: devires insetos para dançar nas fendas imperceptíveis e atravessar fronteiras. In A. C. Reis et al. (Orgs.), Psicologia Social em experimentações: arte, estética e imagem (1a. ed., pp. 522-542). Florianópolis: ABRAPSO: Edições do Bosque $\mathrm{CFH} / \mathrm{UFSC}$.

Guattari, F. (1990). As três ecologias. Campinas, SP: Papirus.

Guattari, F. (2000). Caosmose: um novo paradigma estético. São Paulo: Editora 34.

Guattari, F. \& Rolnik, S. (1999). Cartografias do desejo. Petrópolis, RJ: Vozes.

Haraway, D. (1995). Saberes Localizados: a questão da ciência para o feminismo e o privilégio da perspectiva parcial. Cadernos Pagu, 5, 7-41.

Haraway, D. (2013). Manifesto ciborgue: ciência, tecnologia e feminismo-socialista no final do século XX. In T. Tadeu Silva (Org.), Antropologia do ciborgue (pp. 35-118). Belo Horizonte: Autêntica.

Hernández, F. H. (2013). A investigação baseada em arte: propostas para repensar a pesquisa em educação. In B. Dias \& R. Irwin (Orgs.), Pesquisa Educacional Baseada em Arte: A/r/tografia (pp. 39-62). Santa Maria, RS: Ed. UFSM.

Irwin, R. (2013). A/r/tografia: uma introdução. In B. Dias \& Rita Irwin (Orgs.), Pesquisa Educacional Baseada em Arte: A/r/tografia (pp. 13-23). Santa Maria, RS: Ed. UFSM.

Laurettis, T. (1994). A tecnologia do gênero. In H. Buarque de Hollanda (Org.), Tendências e Impasses: O Feminismo como Crítica da Cultura (pp. 206-242). Rio de Janeiro: Rocco.

Penedo, S. (2008). El Laberintoqueer: La identidadentiempos de neoliberalismo. Barcelona, ESP: Egales.

Preciado, B. (2008). Testo Yonki. Madrid. Espasa Calpe.

Preciado, B. (2011, janeiro-abril). Multidões queer: notas para uma política dos "anormais". Revista Estudos Feministas, 19(1), 11-20.

Preciado, B. (2015). Manifesto Contrasexual — práticas subversivas de identidade sexual. Barcelona, ESP: Esparsa.

Rolnik, S. (1989). Cartografia sentimental: transformações contemporâneas do desejo. São Paulo: Estação Liberdade.

Rolnik, S. (1997). Toxicômanos de identidade. Subjetividade em tempo de globalização." In Daniel Lins (Org.), Cultura e subjetividade. Saberes Nômades (pp. 19-24). Campinas, SP: Papirus.

Rolnik, S. (2002). Subjetividade em obra: Lygia Clark, artista contemporânea. In G. Bartucci (Org.), Psicanálise, Arte e Estéticas de subjetivação (pp. 365-381). Rio de Janeiro: Imago.

Rolnik, S. (2006). Geopolítica da cafetinagem. Núcleo de Estudos da Subjetividade. Recuperado de http://www.pucsp.br/nucleodesubjetividade

Stubs, R. (2015). A/r/tografia de um corpo-experiência. Arte contemporânea, feminismos e produção de subjetividade. Tese de Doutorado, Programa de Pós-graduação em Psicologia, Universidade Estadual Paulista Júlio de Mesquita Filho, Faculdade de Ciências e Letras de Assis, Assis, SP.

Teixeira-Filho, F. (1993). Subjetividade estética e o gesto da sensação Dissertação de Mestrado, Programa de Pós-graduação em Psicologia, Pontifícia Universidade Católica de São Paulo, São Paulo. 


\section{ROBERTA STUBS}

https://orcid.org/0000-0002-1089-5499

Psicóloga com Doutorado em Psicologia com ênfase em arte, gênero e produção de subjetividade pela Universidade Estadual Paulista (Unesp) de Assis, SP.

End.: Rua Rosa Cruz, 826, Maringá-PR-87060-380.

E-mail: rostubs@yahoo.com.br

\section{FERNANDO TEIXEIRA-FILHO \\ https://orcid.org/0000-0003-4975-2273}

Doutor (2000) em Psicologia (Psicologia Clínica) pela Pontifícia Universidade Católica de São Paulo e Livre-Docente (2013) em Psicologia Clínica pela Universidade Estadual Paulista - UNESP. Atualmente é professor adjunto (nível I) na Universidade Estadual Paulista, Faculdade de Ciências e Letras Júlio de Mesquita Filho, em Assis, SP.

E-mail: fteixeira@assis.unesp.br

\section{DOLORES GALINDO \\ https://orcid.org/O000-0003-2071-3967}

Mestre em Psicologia (Psicologia Social) pela Pontifícia Universidade Católica de São Paulo (2002) e doutorado em Psicologia (Psicologia Social) pela Pontifícia Universidade Católica de São Paulo (2006), havendo realizado doutorado sanduíche no departamento de Psicologia Social da Universidade Autônoma de Barcelona (2004). Atualmente é professora do curso de Psicologia e do Programa de Pós-graduação em Estudos da Cultura Contemporânea (ECCO) da Universidade Federal de Mato Grosso, MT.

E-mail: dolorescristinagomesgalindo@gmail.com

\begin{tabular}{|l|l|}
\hline Histórico & $\begin{array}{l}\text { Submissão: 15/11/2016 } \\
\text { Aceite: 12/02/2020 }\end{array}$ \\
\hline Contribuição & $\begin{array}{l}\text { Concepção: R.S.P; F.T.S.F; D.G. } \\
\text { Elaboração do Manuscrito: R.S.P; F.T.S.F; D.G. } \\
\text { Aprovação final do manuscrito: R.S.P; F.T.S.F; D.G. }\end{array}$ \\
\hline Financiamento & FAPESP, no do processo 12/16383-3. \\
\hline $\begin{array}{l}\text { Consentimento } \\
\text { de uso de imagem }\end{array}$ & $\begin{array}{l}\text { Foi obtido o consentimento escrito dos participantes e/ou } \\
\text { do detentor dos direitos autorais sobre a imagem. }\end{array}$ \\
\hline
\end{tabular}

